\title{
A Review of Concerns Related to Chainsaw Lubricants for Sustainable Forest Operation
}

\author{
Seunghyeon Park ${ }^{1}$ and Byoungkoo Choi ${ }^{2 *}$ \\ ${ }^{1}$ Graduate School of Forestry and Environmental Systems, Kangwon National University, \\ Chuncheon 24341, Republic of Korea \\ ${ }^{2}$ Division of Forest Science, Kangwon National University, Chuncheon 24341, Republic of Korea
}

(Received August 28, 2020; accepted November 2, 2020)

Keywords: sustainable forest management, sustainable forest operation, chainsaw, lubricant contamination, lubricant regulation

Machines with an open-cutting system, such as chainsaws and harvesters, are utilized in foresting, gardening, and home and urban landscaping projects. However, these tools require the use of a lubricant, the droplets of which are scattered across the surrounding environment during operation. This use of an oil base and refining additives of petroleum origin in lubricants negatively impacts forest health and the environment. Therefore, the regulation that replaces petroleum-based lubricants with biodegradable lubricants requires improvement in both ecological and economical aspects. Numerous countries have made various efforts to realize sustainable forest management (SFM) and sustainable forest operation (SFO). From the perspective of those working to minimize environmental damage and realize SFO, it has been determined that the negative impact of lubricant droplets that are scattered during forest operations worldwide is not a significant global problem. However, logging is necessary for SFM, and, in many countries, non-biodegradable lubricants are typically used for forest operations because of their lower cost. Thus, to encourage the replacement of the mineral and synthetic oils typically used in forest operations with biodegradable lubricants, price reduction, federal regulations, and considerable research are required. This manuscript is intended to (1) provide information about the effects of lubricants on the environment, (2) raise awareness about the amount of lubricant that can be scattered across ecosystems over a single year of forest operations, and (3) discuss how developed and developing countries differ in terms of their approach to creating and implementing lubricant-use-related regulations. The overall goals of this review are to raise awareness about the need to improve regulations related to lubricants and to find alternatives to mineral-oil- and synthetic-oil-based lubricants. In future studies, it is expected that the area and quantity of lubricant scattered during chainsaw operation can be measured accurately on-site without labor-intensive sampling and subsequent works with more efficient ways using sensing techniques.

*Corresponding author: e-mail: bkchoi@kangwon.ac.kr https://doi.org/10.18494/SAM.2020.3078 


\section{Introduction}

Forests are essential to the long-term well-being of local populations, national economics, and the entire earth's biosphere. When managed sustainably, forests can provide a wide range of economic, social, and environmental goods and services for the benefit of current and future generations. ${ }^{(1)}$ In 1992, the United Nations Conference on Environment and Development raised awareness about the importance of incorporating social values into sustainable forest management $(\mathrm{SFM}){ }^{(2)}$

Because forest management and forest operations are inextricably linked, discussion on the value and idea of sustainable forest operation (SFO) is being heavily promoted. These interests have merged to form the concept of forest operation sustainability. The effective implementation of SFM is dependent on the application of sustainable methods in forest operations. The silvicultural system of forest operations may substantially affect environmental, economic, and social performance characteristics, as well as sustainability. ${ }^{(3)}$

The field of forest operations is defined as a scientific and problem-oriented discipline that serves to provide solutions for technological problems in forestry. ${ }^{(4)}$ Therefore, varying social demands, climate, and working conditions should be considered as major driving factors in the future development of forest operations, as this is necessary to promote economic, environmental, and societal well-being.

Tools with an open-cutting system, such as chainsaws and harvesters, require lubricants and are utilized in forestry, gardening, home landscaping, and urban greenery projects. During their operation, droplets of the lubricants are scattered across the surrounding environment. Consequently, the use of an oil base and petroleum-based refining additives in these lubricants negatively impacts forest health and the environment. In a natural environment, mineral oils, which have low biodegradability, cause primary hazards during forest operations and secondary hazards through their accumulation in groundwater and plant and animal tissues in the surrounding environment. ${ }^{(5)}$ In terms of the physical properties of soil, mineral oil can occlude soil pores, resulting in a reduced aeration and water infiltration capacity. ${ }^{(6)}$ Subsequently, these cause secondary hazards through rainfall or storms. When soil contaminated by lubricants is eroded and transported to water systems, it can result in the critical contamination of drinking water. ${ }^{(7)}$ Lubricants also can affect vegetation and plants by changing the physicochemical properties of the soil. Certain differences can occur depending on the species, initial plant growth, and germination; physiological properties are also negatively affected. ${ }^{(8,9)}$ The replacement of petroleum-based lubricants with biodegradable lubricants requires improvement from both ecological and economic perspectives. Above all, technical efforts are needed to improve the properties of biodegradable lubricants to the level of mineral lubricants mainly used so far. In terms of economic, efforts are required in various parts to lower the price of biodegradable lubricants. For example, there are ways to impose sanctions such as fines or to provide subsidies by redefining regulations on the use of petroleum-based oil. Also, there are other ways to mass-produce biodegradable lubricants at low prices through technological improvements. Another way is to create exact standards that can be used for measuring the area and quantity of scattered lubricant using advanced technologies such as radar scanning. In this 
paper, we focused on improvements in both economic and ecological aspects by implementing regulations to improve people's awareness.

The environmental performance of a forest operation is evaluated on the basis of local, regional, and global environmental impact minimization. There are six areas of consideration in this performance evaluation: energy consumption, soil, air, water, remaining stand and regeneration capacity, and biodiversity. Among these, energy consumption and soil are directly affected by the lubricant. In the case of energy consumption, the amounts of lubricant and renewable energy consumed during operation are taken into account with respect to the timber volume; in the case of soil, the levels of contamination and modification of its physicochemical and biological properties are considered. ${ }^{(3)}$

SFOs should maximize ecosystem services and increase the public recognition of wellmanaged forests. It is also important to note that various stakeholders are involved in decisions related to forest operations, that SFOs must comply with existing laws and regulations, and that SFOs require improvement and monitoring through certification processes. ${ }^{(3)}$

The European Union (EU) revised EU ecolabel criteria for lubricants in 2018 by preparing a preliminary technical report on ecolabeling lubricants; this report covered product group classification, scope, and definitions. According to this report, lubricant products should be classified as total loss lubricants (TLLs), partial loss lubricants, or accidental loss lubricants. The TLL group comprises chainsaw oils, wire rope lubricants, concrete release agents, total loss greases, and other TLLs. TLLs are most commonly used in chainsaws purposed for forest operations. $^{(10,11)}$

In 1995, some researchers reported on the environmental damage caused by these lubricants. According to their research, a ban on chainsaw lubricants will, at best, yield a net neutral effect on the environment. Thus, six environmentally related considerations were suggested: (1) production should be environmentally neutral, (2) renewable resources should be employed where feasible, (3) the lubricant should be physiologically harmless, (4) the lubricant should be (eco-)toxicologically acceptable, (5) the lubricant should biodegrade rapidly, and (6) there should be no disposal problems. These environmental considerations focused on health and water hazards. $^{(12)}$ At present, developed countries tend to be more compliant with these environmental considerations, whereas some developing countries are implementing the past regulations of developed countries, and the remaining countries need even more regulations.

The aims of this review are (1) to provide information about the effects of chainsaw lubricants on the environment, (2) to raise awareness about the amount of lubricant that can be scattered across ecosystems over a single year of forest operations, and (3) to discuss how lubricant-use-related regulations differ between developed and developing countries.

\section{Characteristics of Lubricants}

Lubricants act as the fluid component of machines and devices. Specifically, they create a film layer between the moving parts of a device. Owing to their specialized properties, lubricants are able to perform many functions, such as the minimization of friction, the prevention of scuffing on the surfaces of two contacting elements, the washing of carbon 
deposits and microparticles, the prevention of corrosion, and cooling. Additionally, lubricants must be developed in consideration of their environmental impact and application properties. ${ }^{(13)}$

Lubricants comprise a mixture of a base oil (>85\%) and enriching additives. ${ }^{(14-16)}$ In general, the toxicological potential of lubricants, base oils, and additives must be considered. ${ }^{(12)}$ The purpose of incorporating additives is to improve the quality of lubricants, and the process of organically synthesizing these additives is often expensive. In general, refined additives can be synthetic, organic, or metal-organic chemicals, or products of natural raw materials. The types of additives include oxidation inhibitors, rheology modifiers, depressants, detergents, dispersants, de-emulsifiers, emulsifiers, lubricants, anti-wear agents, anti-seize compounds, friction modifiers, corrosion and rust inhibitors, passivators, anti-foaming agents, dyes, fragrances, and other multifunctional additives. ${ }^{(13)}$ Additionally, refined additives of natural origin can be useful alternatives to petroleum-based products. ${ }^{(17)}$

In general, the global lubricant market is dominated by petroleum-based products. Most of the lubricant base oils are produced during crude oil processing, and these base oils are much lower in cost than synthetic or natural base oils. ${ }^{(18,19)}$

Most existing lubricants comprise a material with an oily consistency, a characteristic chemical composition, and lubricating properties; additionally, lubricants can be classified according to the type of constituent oil, i.e., mineral oils, synthetic oils, or oils of natural origin. ${ }^{(19)}$

Lubricants produced from crude oil are commonly referred to as mineral oils and are subjected to conventional oil-refining processing methods. Regarding their composition, they are mainly mixtures of liquid, low-volatile aliphatic hydrocarbons, and alicyclic, aliphatic substituted hydrocarbons that are produced during distillation at a temperature above $360{ }^{\circ} \mathrm{C} .{ }^{(13)}$ Mineral oils contain many classes of chemical compounds, including paraffins, naphthenes, aromatic compounds, and heteroatomic compounds. There are various processing technologies and types of petroleum bases; thus, mineral oils can have diverse compositions that may include branched-chain aliphatic-aliphatic and alicyclic-alicyclic hydrocarbons, and aliphatic or alicyclic aromatic hydrocarbons. These kinds of hydrocarbons are mainly derivatives of benzene, biphenyl, diphenylmethane, triphenylmethane, naphthalene, anthracene, phenanthrene, and chrysene. ${ }^{(14,20)}$

These chemical compounds, which are sourced from crude oil, negatively impact the environment and human health. ${ }^{(21)}$ Nevertheless, the need to increase the device efficiency and the demand for more efficient lubricants have increased. Synthetic-oil-based lubricants have been created to maximize lubricating performance and economic benefit, and improve performance.

Synthetic bases such as poly-alpha-olefins (PAOs), alkylated aromatics, esters, polyglycols, polybutenes, and polynectolefines are widely used in the lubricant industry. ${ }^{(14,20,22)}$ Synthetic oils are synthesized from petrochemical industry raw materials or via the hydrocatalytic process of hydrocarbon backbone conversion from natural gas. ${ }^{(14)}$ Globally, more than $80 \%$ of synthetic base oils are produced from three main classes of materials, i.e., PAOs (45\%), esters, including dibasic and polyol esters (25\%), and polyalkylene glycols (PAGs) $(10 \%) .{ }^{(23)}$ The most popular fully synthetic oils are PAO oils. The efficiency and cost of these oils are relatively high, but some synthetic oils can pose a threat to the environment. ${ }^{(18)}$ 
The biodegradability rate and physicochemical properties, such as the viscosity index range, dynamic viscosity at negative temperatures, melting temperature, flashpoint, evaporability, and basic or acidic number, must be precisely and accurately predicted prior to the commercial release of a lubricant. ${ }^{(14)}$

An increase in public awareness about the impact of lubricants on the environment and human health has pushed researchers, and the industry as a whole, to develop fully biodegradable lubricants of natural origin. ${ }^{(14)}$ More specifically, the public has become concerned about lubricants entering the biosphere as a result of forest operations, industrial accidents, and oil spills in water bodies. ${ }^{(13)}$ Consequently, the acceptance and usage of biodegradable products have been growing, especially in European forestry.

According to previous reports, vegetable oils have a biodegradation rate that is $70-100 \%$ higher than those of other types of base oils; additionally, vegetable base oils comprise triacylglycerols and their derivatives, i.e., diacylglycerols, monoacylglycerols, free fatty acids, and liquid glycerol, at room temperature. ${ }^{(14,24)}$ The primary advantage of vegetable base oils is that they are environmentally friendly; in particular, they have high biodegradability and low toxicity in an aquatic environment. ${ }^{(14)}$ Furthermore, these oils are known to have good lubricity, high efficiency over a wide temperature range, high viscosity index, and polarity, which ensures a high cleaning effect. However, these oils are natural products; therefore, their chemical composition may differ according to the crop type. Moreover, the prices of vegetable oil products vary; in general, they are approximately twice the cost of petroleum-based oils. ${ }^{(19)}$

As previously intimated, forest-operation-purposed machines disperse lubricants that penetrate soils, infiltrate water systems, and may harm the ecosystem. ${ }^{(10)}$ Therefore, from the perspective of environmental protection, these lubricants should rapidly and easily biodegrade. ${ }^{(25)}$ Moreover, legislative bodies should enact regulations that encourage the use of biodegradable lubricants and establish practical procedures for the supervision and quality control of lubricants, especially those that are prone to infiltrating ecosystems, so that they can be applied in field operations and production processes. ${ }^{(13)}$

Note that there are differences in how developed and developing countries regulate lubricating oil. These regulatory differences consequently translate to differences in the type and amount of environmental damage caused by lubricants. It is for this reason that, as previously mentioned, research and regulations should be purposed to reduce the cost of biodegradable lubricants.

\section{Quantity of Lubricant Scattered by Forest Operations}

In the past, most of the public attention was focused on the threat of large oil spills and related problems. However, current circumstances mandate that low-level pollution sources are also considered to be serious problems. The main problem here is the lack of ability to conduct the necessary research on contamination. ${ }^{(13)}$

As lubricant use is imperative when trees are harvested, the global statistics on the amount of lubricant that is scattered across environments as a result of forestry projects can be represented by the global statistics for roundwood removal (Fig. 1). For this review, statistics on the removal 


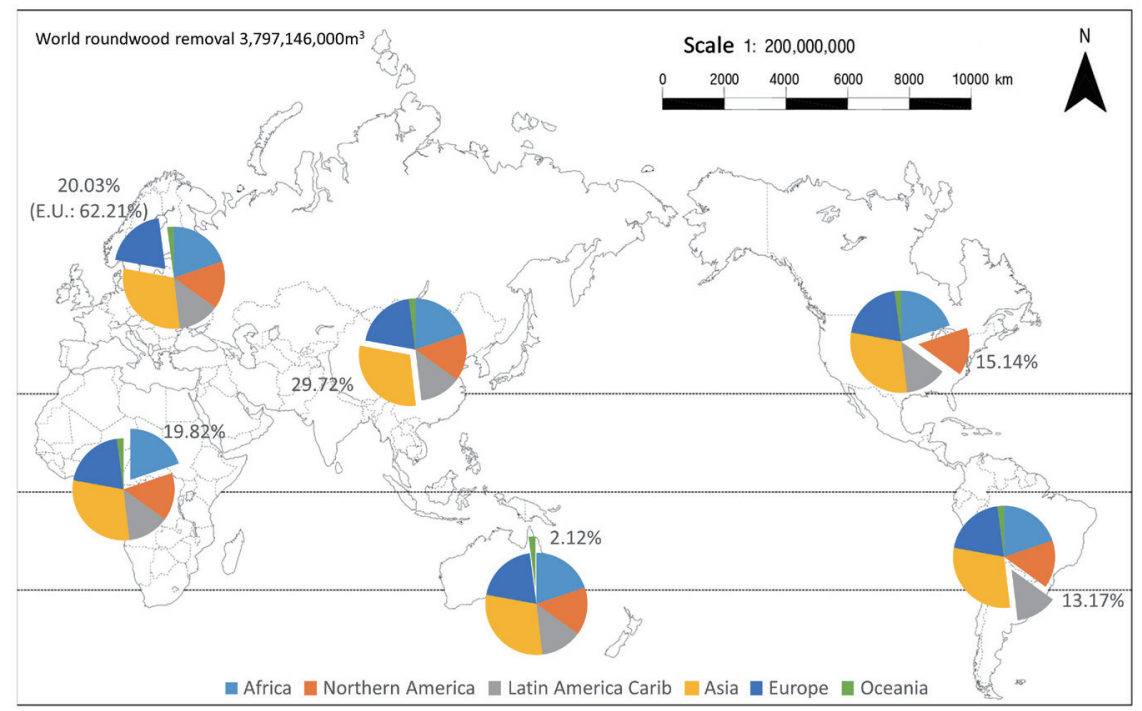

Fig. 1. (Color online) Roundwood removal by continent during 2017. According to the statistical yearbook of forest product production from FAO, roundwood removal worldwide in 2017 was $3.8 \times 10^{9} \mathrm{~m}$. The percentage shown in each pie chart represents the ratio of worldwide roundwood removal for each continent. The largest amount of removal is in Asia, at 29.7\%, followed by Europe with $20 \%$ (62.2\% of it from EU member countries), Africa with 19.8\%, Northern America with 15.1\%, Latin America Caribbean with 13.2\%, and Oceania with 2.1\%.

of roundwood in Asia, Europe, Africa, North America, South America and the Caribbean, Oceania, and EU countries (the removal of roundwood from EU countries accounted for $62.2 \%$ of Europe) were evaluated. ${ }^{(26)}$

A chainsaw requires $0.05 \mathrm{~L}$ of lubricant to obtain $1 \mathrm{~m}^{3}$ of wood, whereas a harvester requires less than half of this amount (i.e., only $0.02 \mathrm{~L}$ ). On the basis of this assumption, on average, $1 \mathrm{~m}^{3}$ of secondary oil requires $0.035 \mathrm{~L}$ of lubricant; therefore, annually, $132900000 \mathrm{~L}$ of lubricant enters the biosphere (Fig. 2). ${ }^{(13)}$

\section{Effects of Lubricant on Forest Ecosystems}

Lubricants become dispersed throughout the environment in the form of oil mist and droplets, which negatively impact the environment. The effects and intensity of interactions among lubricant compounds are highly dependent on the composition, emission volume, and frequency in a given area, as well as various features of the open-cutting device. ${ }^{(13)}$

In a natural environment, mineral oils, which have low biodegradability, cause primary hazards during forest operations and secondary hazards through their accumulation in groundwater and the tissues of plants and animals in the surrounding environment. ${ }^{(10)}$ Moreover, these oils also pose a very significant threat to aquatic ecosystems; for example, water containing $1 \mathrm{ppm}$ of oil is considered to be contaminated. ${ }^{(10)}$

Soil is a very complex system with extremely high biodiversity. Consequently, soil remediation, and more specifically, the removal of petroleum contaminants, is a difficult and long-lasting process. ${ }^{(27)}$ Moreover, petroleum-based oil contaminants are detrimental 


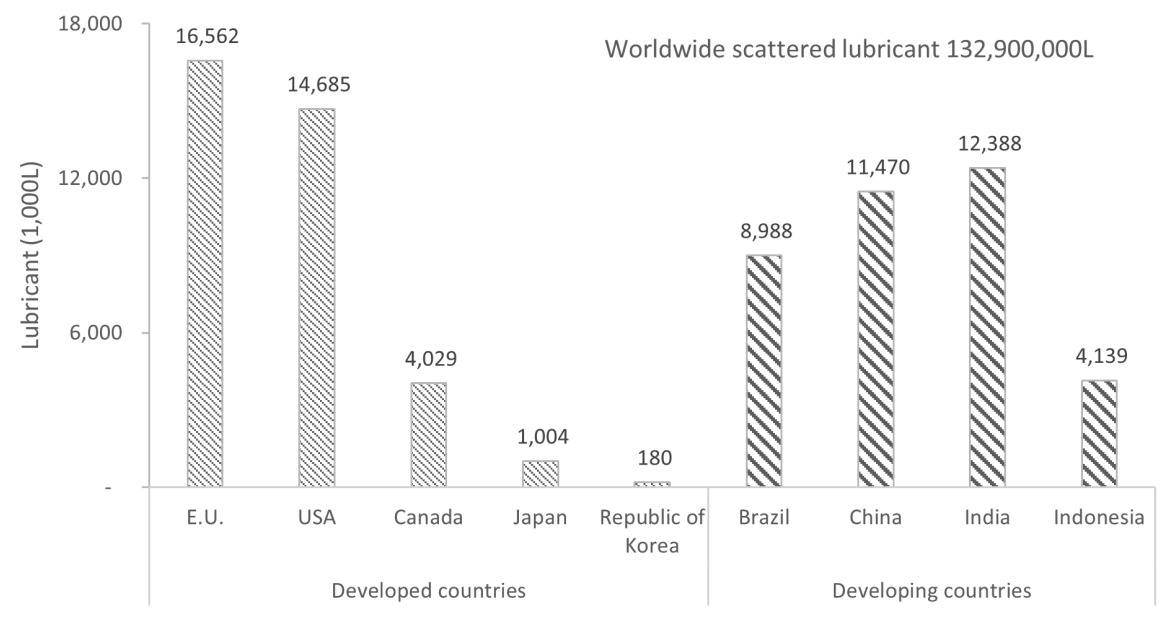

Fig. 2. Comparison of amounts of lubricant used for forest operation during 2017. The amount of scattered lubricants worldwide in 2017 was $1.3 \times 10^{8} \mathrm{~L}$. The quantities of lubricant scattered on forest ecosystems were calculated assuming that, on average, $1 \mathrm{~m}^{3}$ of secondary oil requires $0.035 \mathrm{~L}$ of lubricant during forest operations. ${ }^{(13)}$

to soil biodiversity because they induce multiple physicochemical changes by modifying the distribution of organic matter such as carbon, water, nitrogen, and phosphorus. As previously mentioned, this type of pollution may not only critically impact biodiversity but also disrupt the function of the ecosystem. In terms of the physical properties of soil, mineral oils can occlude soil pores, resulting in a reduced aeration and water infiltration capacity. Consequently, permeability is reduced and soil degradation occurs as a result of oxygen deficiency. ${ }^{(6)}$ In addition, hydrocarbon contamination through mineral oil introduction causes soil to become water-repellent, thereby reducing the soil moisture retention capacity at low levels of soil suction. At $100 \mathrm{~g} / \mathrm{m}^{2}$, a mineral oil was found to reduce the air-filled soil porosity by $4 \%$; the largest amount of oil $\left(200 \mathrm{~g} / \mathrm{m}^{2}\right)$ was found to reduce the air-filled soil porosity by nearly $10 \%$ relative to non-contaminated soil. ${ }^{(28)}$ This means that rainfall or storms may trigger erosion and transport contaminants to nearby water bodies or groundwater systems, resulting in the critical contamination of drinking water. ${ }^{(12)}$ Regarding the effects of erosion, the presence of understory in the contaminated area may help to regulate the flow of water to surface water. Furthermore, vegetation roots serve to inhibit topsoil erosion. However, when rainfall causes flooding in harvested sites, topsoil that is not protected by vegetation is easily eroded; this soil disruption may negatively affect road construction projects, transport contaminants along with the topsoil, and exacerbate various problems, causing landslides and creep. ${ }^{(13)}$

Lubricant contaminants in soil also affect vegetation by changing the physicochemical properties of the soil. Oil contamination at $4-5 \% \mathrm{w} / \mathrm{w}$ was previously reported to consistently inhibit the germination of hot peppers (Capsicum annum L.) and tomatoes (Lycopersicon esculentum Miller). For hot pepper plants that germinated in oil-contaminated soil, the mean height and leaf area were measured to be small 48 days after seeding and all tomato plants were observed to die prematurely. ${ }^{(29)}$ In other reports, Ricinus communis L. grown in oilcontaminated soil at a minimum of $2 \% \mathrm{w} / \mathrm{w}$ had smaller plant height and stem girth than the 
control group. ${ }^{(30)}$ Furthermore, mangroves growing in oil-contaminated soil showed different symptoms according to the species and soil type. One such species, B. gymnorrhiza, showed a distinctly severe reaction to lubricants. When treated with a single initial lubricant dose of $5 \mathrm{~L} / \mathrm{m}^{2}$, the plant height, the number of leaves, and the biomass decreased significantly during the initial growth period, and the malondialdehyde content, free radical activity, and antioxidant enzyme activity increased in the same period. ${ }^{(8)}$ Moreover, lubricants also affected the germination of Gmelina arborea. The success of germination was dependent on the lubricant dose. In $9 \% \mathrm{w} / \mathrm{w}$ of lubricant, at least $41.3 \%$ of seeds germinated; however, no germination was observed in $12 \% \mathrm{w} / \mathrm{w}$ of lubricant. ${ }^{(9)}$

These lubricant-contamination-related effects on the environment are also dependent on the extent of heavy metal contamination. Heavy metals readily interact with the hydrocarbons in lubricants but hardly bond with these compounds. ${ }^{(31,32)}$

Although it is known that lubricants negatively impact the environment, that more comprehensive studies on their use are required, and that they need to be appropriately regulated, few countries are currently enacting lubricant regulations to protect the environment.

\section{Regulations}

As stated, scattered lubricant droplets pollute soil and water systems, and governments worldwide need to develop regulations, standards, rules, and so forth to reduce the risks of contamination and pollution. However, it is difficult to treat water bodies and groundwater that have been contaminated by the lubricants used in timber-harvesting tools. This is because rainfall and wind storms cause these pollutants to be transported along with soil particles from harvested sites to watersheds and groundwater. Thus, proper lubricant-related regulations are required to reduce their negative effects, as lubricants are not biodegradable or eco-friendly. Furthermore, these regulations must mandate the use of alternatives to mineral and synthetic oils to reduce the risk posed to the environment.

As previously mentioned, we evaluated the global statistics on roundwood removal to investigate whether countries with relatively developed and developing forestry programs had any regulations related to the use of lubricating oil during forest operations. We assumed that the level of development of the forestry program was representative of the related technical skills of the relevant country. Consequently, the EU, the United States (US), Canada, Japan, and South Korea were classified as countries with developed forestry programs, whereas Brazil, China, India, and Indonesia were classified as countries with developing forestry programs.

\subsection{Developed countries}

\subsubsection{EU member countries}

The demand for environmentally friendly lubricants is steadily increasing in Europe, particularly for use in agricultural, earthmoving, and construction machinery, as well as for chainsaws, motorboats, railway switchgear, and concrete molds. Europeans began to show 
interest in biodegradable lubricants in the 1980s. Biodegradable lubricants were initially accepted in Northern Europe, then public pressure to protect the environment by using biodegradable lubricants spread to other parts of Europe. Consequently, Sweden introduced the first lubricant of natural origin in 1988 when they began using rapeseed-oil-based hydraulic fluids. During the preparation of this review, we found that Sweden had the strictest lubricant-use-related regulations. Specifically, in Sweden, nearly all forestry operations use environmentally friendly lubricants, including gear and chain bar oils, because they are currently mandated for all forestry operators. ${ }^{(33)}$

The biodegradability of lubricants has been assessed through the implementation of standard tests. The Coordinating European Council developed biodegradation test methods by utilizing Organization for Economic Cooperation and Development (OECD) 301 A-F methods. These methods assess biodegradability by injecting the prescribed oil into specific microorganisms and studying its biodegradation over a period of $28 \mathrm{~d}$ on average. Consequently, after $28 \mathrm{~d}$, any lubricant with approximately $60 \%$ degradation means that $40 \%$ of the lubricant remains in the environment. This also indicates that the biodegradation rate may be undesirably low. After performing this test, it was found that, even if the amount of lubricant that contaminates that environment is reduced, fundamentally, there is no way to solve the pollution problem. ${ }^{(10,34)}$

To overcome these problems, the EU has been continuously developing their regulations on lubricants. To support this, the EU has recently revised the European ecolabel criteria for lubricants. The current criteria focus on two main aspects. First, the scope of applicable lubricants was expanded to cover a higher market share of lubricants; this resulted in the establishment of three main categories of lubricants (i.e., TLLs, partial loss lubricants, and accidental loss lubricants) that differed according to the risk that the lubricant poses to the environment. Secondly, to clearly define the covered categories, a definition of each category was added to the complementary definitions section. These revisions have consequently extended the applicability of EU ecolabels to cover more lubricants and have clarified some of the ambiguity surrounding the types of lubricants covered by these revisions. ${ }^{(11)}$

\subsubsection{US}

To date, the US has tended to focus on water pollution. They have described the implementation of specific environmentally preferable lubricants as best management practices (BMPs). The US has also described the standards related to the biodegradability, toxicity, and bioaccumulation potential of BMPs that minimize the probable negative impact on water systems, and performed comparative analysis using conventional lubricants. Because much of the lubricant spilled from a vessel is directly transported to water systems, the US has focused on encouraging the implementation of environmentally acceptable lubricants (EALs) on vessels. In any case that a lubricant has direct access to water, the implementation of EALs with a biodegradable oil base, such as vegetable oils, biodegradable synthetic esters, or biodegradable PAGs, as opposed to mineral oils, has been demonstrated to reduce the environmental impact. Although the results of their research have increased the use of EALs, they continue to make up a small share of the lubricant market. ${ }^{(35)}$ 
The US employs generalized test methods developed by the OECD, Coordinating European Council, and American Society for Testing and Materials to ascertain lubricant biodegradability. There are two types of tests, i.e., ready biodegradability and hydrocarbon degradability screening tests. OECD 301 A-F, ASTM D-5864, and EPA 560/6-28-003 are used to evaluate the ready biodegradability. Complete mineralization rates are defined as up to 60 to $70 \%$. Alternatively, CEC L-33-A-934 is used to evaluate the hydrocarbon degradability. According to this standard, complete mineralization rates are defined as up to $80 \%{ }^{(35)}$ The biodegradability, potential for bioaccumulation and the toxicity of each type of lubricant were summarized by Mudge $^{(36)}$ (Table 1).

Although Japan, South Korea, and Canada have relatively developed forestry programs, there are few lubricant-use-related regulations for forest operations. In the case of Japan, the concept of EALs was introduced by the US; however, Japan has yet to enact most of the regulations within the country. In South Korea, research is currently underway to assess the damage caused by lubricant contamination; more specifically, current research is focused on risk assessment methods and the development of petroleum total hydrocarbons. ${ }^{(37)}$ However, at present, there are few federal regulations related to the use of lubricants in tools purposed for forest operations.

In addition to the above-mentioned regulations, other efforts are being made to reduce the environmental pollution caused by lubricants. One approach is related to labeling. To specify and label environmentally acceptable products, authorities and institutions in different countries have created environmental labeling schemes and various marks/labels. These labels were designed to garner the interest of lubricant suppliers and EAL users. ${ }^{(12)}$

\subsection{Developing countries}

The main problem related to the use of lubricants in developing countries is the price of biodegradable lubricants. This is because it is common practice in most developing countries to prioritize economic burden over environmental impact. Because of this, regulations that encourage the use of biodegradable lubricants, as well as research to find alternatives for mineral and synthetic oils, are required.

Table 1

Biodegradation, potential for bioaccumulation, and toxicity of different lubricant base oils. ${ }^{(36)}$ Lubricants are categorized into four types: mineral oils, PAGs, synthetic esters, and vegetable oils. The main factor to consider is the base oil, which leads to differences in biodegradation, the potential for bioaccumulation, and toxicity. In particular, mineral oils showed contrary results to the other lubricants in biodegradation, the potential for bioaccumulation, and toxicity.

\begin{tabular}{lcccc}
\hline Lubricant & Base oil & Biodegradation & $\begin{array}{c}\text { Potential for } \\
\text { bioaccumulation }\end{array}$ & Toxicity \\
\hline Mineral oils & Petroleum & Persistent/inherent & Yes & High \\
PAGs & $\begin{array}{c}\text { Petroleum-synthesized } \\
\text { hydrocarbons }\end{array}$ & Readily & No & Low \\
Synthetic esters & $\begin{array}{c}\text { Synthesized } \\
\text { from biological sources } \\
\text { Naturally occurring } \\
\text { vegetable oils }\end{array}$ & Readily & No & Low \\
Vegetable oils & Readily & No & Low \\
\hline
\end{tabular}


China and India are very important countries in Asia, and they continue to be active in forestry. However, as compared with their levels of economic activity, they are relatively indifferent to the environment. Although the amount of roundwood removal in each of these countries exceeded $3 \times 10^{6} \mathrm{~m}^{3}$ in $2017,{ }^{(26)}$ it is unclear whether the environmental impact is considered or whether regulations related to the use of lubricants during forest operations are enforced. Despite this uncertainty, we found that both countries have conducted many studies on soil contamination and biodegradable lubricants.

Some researchers in China have reported on the need for regulations to evaluate soil contaminated by petroleum-based hydrocarbons, including those contained in lubricants. ${ }^{(38-40)}$ They also reported on the feasibility of using biodegradable lubricants to estimate the physicochemical properties of vegetable oils ${ }^{(41,42)}$ and studied technical report. ${ }^{(43)}$ India has also demonstrated efforts to improve environmental conditions, as some researchers have reported on the importance of using environmentally friendly lubricants. ${ }^{(44-46)}$

In Indonesia, the environmental impact of lubricants does not seem to be important, as they have problems that are much more serious than lubricant contamination. Large-scale palm oil and timber plantations in the region have contributed to more than two-fifths of global deforestation between 2001 and 2016, with a peak in the rate followed by a notable decline up to 2016. ${ }^{(47)}$ Although they are primarily focused on solving these problems, Indonesian researchers have conducted a few studies on biodegradable lubricants. ${ }^{(48-50)}$

Regarding Brazil, biodegradable lubricants are mentioned in legislative documents; however, we found that related regulations did not exist, and that there was a lack of awareness about the environmental impact of lubricants. This is because Brazil is a crude oil producer and is thus more interested in producing and exporting crude oil. ${ }^{(51)}$

Thus, although many people in Brazil are aware of the effects of waste oil on different types of ecosystems, such as soil and water systems, as well as the need for regulations, ${ }^{(52)}$ it is difficult to expect the governing authorities to create legislation that regulates lubricant use during forest operations.

Although all of the governing bodies investigated for this review had relatively developed forestry programs, most of them did not regulate the lubricants used during forest operations. Regarding the environmental impact of forestry-purposed tool lubricants, a considerable amount of research related to pollution and remediation methods has been conducted; however, the research focused on crude oil or waste oil contamination, and reports on regulations tended to focus on the pollution caused by crude oil spills in the ocean. Nevertheless, we assume that the lack of public interest in the problem of lubricant pollution associated with forest operations has led to a lack of regulations.

\section{Conclusions}

Various efforts have been made to realize SFOs worldwide. From the environmental perspective, it has been determined that the negative impact of lubricants that enter the biosphere during forest operations has not been given adequate consideration. In 2017, $1.32 \times 10^{8} \mathrm{~L}$ of lubricants entered the biosphere as a result of chainsaw and harvester use during forest operations. The dispersed lubricants may contaminate soil and vegetation, which can be transported, along with soil particles, to water bodies by rainfall or wind; these 
conditions can even create the secondary hazard of water pollution. Nevertheless, logging is necessary for SFM, and, in many countries, the economic burden associated with the use of biodegradable lubricants for forest operations prevents their use. Thus, to replace the mineral and synthetic oils used during forest operations with biodegradable lubricants, various efforts are needed for both ecological and economic aspects. For example, in terms of technology, it is necessary to improve the properties of biodegradable lubricants to the level of the mineral lubrication properties or to develop technologies to mass-produce biodegradable lubricants at low prices. However, the first step in this effort is to make people aware of the problem and thereby to inspire the need for legislation. During the preparation of this review, studies on biodegradable lubricants were underway in technologically advanced countries; however, the EU and US were the only regulatory bodies to have created legislation that regulates lubricant use. EU member countries have been particularly active in encouraging strong regulations to protect the environment; furthermore, the OECD and EU have been leading the way in the creation of regulations and standards purposed to prevent environmental damage caused by lubricants. Non-EU member countries were found to have few regulations related to the use of biodegradable lubricants during forest operations, and only a few countries have demonstrated any interest in implementing the standards and regulations created by the EU and US. Thus, as a result of considering the environmental impact of scattered lubricant droplets, as well as how these droplets affect SFM and SFO, we conclude that the lack of adequate regulations is not restricted to developing countries and that the countries with regulations related to the use of lubricants during forest operations need to tighten them and enforce them more strictly. Moreover, the adequacy of regulations requires not only people's awareness but also standards for lubricants scattered during forest operation. To set standards, accurate technologies that can measure the scattered lubricant are needed. Existing technologies were used to collect soils onsite and analyze them in laboratories, which is time-consuming and expensive. Therefore, in future studies, it is necessary to apply more advanced efforts such as sensing techniques. For example, when tracking lubricant scattering during chainsaw operation by rapidly developed remote sensing technology as a radar, it is expected that the area and quantity of lubricant scattering can be measured accurately on-site without labor-intensive sampling and subsequent works.

\section{Acknowledgments}

This research was supported by the Basic Science Research Program through the National Research Foundation of Korea (NRF) funded by the Ministry of Education (NRF2018R1D1A1B07041766). This research was also supported by a 2015 Research Grant from Kangwon National University.

\section{References}

1 Montreal Process: Criteria and indicators for the conservation and sustainable management of temperate and boreal forest, Fifth Edition (Montreal Process, 2015) p. 5. https://www.montrealprocess.org/The_Montreal_ Process/Criteria_and_Indicators/index.shtml

2 S. Wang: For. Policy. Econ. 6 (2004) 205. https://doi.org/10.1016/j.forpol.2004.03.004

3 E. Marchi, W. Chung, R. Visser, D. Abbas, T. Nordfjell, P. S. Mederski, A. McEwan, M. Brink, and A. Laschi: Sci. Total Environ. 634 (2018) 1385. https://doi.org/10.1016/j.scitotenv.2018.04.084 
4 H. R. Heinimann: Croat. J. For. Eng. 28 (2007) 107. https://hrcak.srce.hr/11558

5 E. O. Aluyor and M. Ori-Jesu: Afr. J. Biotechnol. 8 (2009) 915. https://www.ajol.info/index.php/ajb/article/ view/59986

6 E. E. Abosede: IOSR. J. Agric. Vet. Sci. 6 (2013) 14. http://doi.org/10.9790/2380-0631417

7 A. Takawira, W. Gwenzi, and P. Nyamugafata: Geoderma 235 (2014) 279. https://doi.org/10.1016/ j.geoderma.2014.07.023

8 C. G. Zhang, K. K. Leung, Y. S. Wong, and N. F. Y. Tam: Environ. Exp. Bot. 60 (2007) 127. https://doi. org/10.1016/j.envexpbot.2006.09.002

9 O. M. Agbogidi: AJNS 12 (2015) 11. http://www.ajns.org.ng/ojs/index.php/AJNS/article/view/3

10 V. A. G. Candela, D. Nicholas, and W. Oliver: Joint Research Centre (2020). http://doi.org/10.2760/483848

11 V. A. G. Candela, K. R. Barbara, K. Oyeshola, W. Oliver, R. M. Rosa, H. Carme, F. Natalia, E. Marta, J. Gemma, J. Jaume, and B. Elisabet: Joint Research Centre (2018). http://doi.org/10.2760/58736

12 W. J. Bartz: Tribol. Int. 31 (1998) 35. https://doi.org/10.1016/S0301-679X(98)00006-1

13 P. Nowak, K. Kucharska, and M. Kamiński: Int. J. Environ. Res. Pub. He. 16 (2019) 3002. https://doi. org/10.3390/ijerph16163002

14 E. Beran: Tribol. Int. 41 (2008) 1212. https://doi.org/10.1016/j.triboint.2008.03.003

15 Z. Tang and S. Li: Curr. Opin. Solid State Mater. Sci. 18 (2014) 119. https://doi.org/10.1016/j.cossms.2014.02.002

16 N. A. Zainal, N. W. M. Zulkifli, M. Gulzar, and H. H. Masjuki: Renewable Sustainable Energy Rev. 82 (2018) 80. https://doi.org/10.1016/j.rser.2017.09.004

17 C. Vasile, M. Sivertsvik, A. C. Miteluţ, M. A. Brebu, E. Stoleru, J. T. Rosnes, E. E. Tanase, W. Khan, D. Pamfil, C. P. Cornea, and A. Irimia: Materials 10 (2017) 45. https://doi.org/10.3390/ma10010045

18 G. E. Totten, S. R. Westbrook, and R. J. Shah: Fuels and Lubricants Handbook: Technology, Properties, Performance, and Testing (Astm Intl, 2003) p. 207.

19 S. Garrett: US Department of Agriculture, Forest Service, San Dimas Technology and Development Center (1998). https://www.fs.fed.us/eng/pubs/html/98511316/98511316.html

20 R. M. Mortier, S. T. Orszulik, and M. F. Fox: Chemistry and Technology of Lubricants Vol. 107115 (Springer, Heidelberg, 2010) p. 56.

21 A. Z. Syahir, N. W. M. Zulkifli, H. H. Masjuki, M. A. Kalam, A. Alabdulkarem, M. Gulzar, L. S. Khuong, and M. H. Harith: J. Clean. Prod. 168 (2017) 997. https://doi.org/10.1016/j.jclepro.2017.09.106

22 L. R. Rudnick: Synthetics, Mineral Oils, and Bio-based Lubricants: Chemistry and Technology (CRC press, Boca Raton, 2020) p. 1.

23 M. M. Wu, S. C. Ho, and T. R. Forbus: Synthetic Lubricant Base Stock Processes and Products. In Practical Advances in Petroleum Processing (Springer, New York, 2006) p. 553.

24 C. H. Chan, S. W. Tang, N. K. Mohd, W. H. Lim, S. K. Yeong, and Z. Idris: Renewable Sustainable Energy Rev. 93 (2018) 145. https://doi.org/10.1016/j.rser.2018.05.024

25 J. Iłowska, J. Chrobak, R. Grabowski, M. Szmatoła, J. Woch, I. Szwach, J. Drabik, M. Trzos, R. Kozdrach, and M. Wrona: Molecules 23 (2018) 2025. https://doi.org/10.3390/molecules23082025

26 FAO: Statistical Yearbook of Forest Product Production (Food and Agriculture Organization of The United Nations, Rome, 2019) p. 100.

27 G. Gordon, I. Stavi, U. Shavit, and R. Rosenzweig: Geoderma 312 (2018) 114. https://doi.org/10.1016/ j.geoderma.2017.10.008

28 A. Klamerus-Iwan, E. Błońska, J. Lasota, A. Kalandyk, and P. Waligórski: Water, Air, Soil Pollut. 226 (2015) 389. https://doi.org/10.1007/s11270-015-2649-2

29 G. O. Anoliefo and D. E. Vwioko: Environ. Pollut. 88 (1995) 361. https://doi.org/10.1016/0269-7491(95)93451-5

30 D. E. Vwioko, G. O. Anoliefo, and S. D. Fashemi: J. Appl. Sci. Environ. Manage. 10 (2006) 127. http://doi. org/10.4314/jasem.v10i3.17331

31 M. Malawska and B. Wiołkomirski: Water Air Soil Pollut. 127 (2001) 339. https://doi.org/10.1023/ A:1005236016074

32 L. Sun, X. Liao, X. Yan, G. Zhu, and D. Ma: Environ. Sci. Pollut. Res. 21 (2014) 12494. https://doi.org/10.1007/ s11356-014-3171-6

33 R. D. Whitby: Tribol. Lubr. Technol. 60 (2004) 64. https://search.proquest.com/ docview/226971975?accountid=7411

34 EPA: United States Environmental Protection Agency (2011). https://nepis.epa.gov/Exe/ZyNET.exe/P100DCJI. TXT?ZyActionD=ZyDocument $\&$ Client $=$ EPA $\&$ Index $=2011+$ Thru $+2015 \&$ Docs $=\& Q u e r y=\&$ Time $=\&$ EndTime $=$ $\&$ SearchMethod $=1 \&$ TocRestrict $=$ n $\&$ Toc $=\&$ TocEntry $=\& Q$ Field $=\&$ QFieldYear $=\& Q$ FieldMonth $=\& Q$ FieldDay $=$ $\&$ IntQFieldOp $=0 \&$ ExtQFieldOp $=0 \& X m l Q u e r y=\& F i l e=D \% 3 \mathrm{~A} \% 5$ Czyfiles $\% 5 \mathrm{CIndex} \% 20 \mathrm{Data} \% 5 \mathrm{C} 11$ thru $15 \%$ 5CTxt\%5C00000003\%5CP100DCJI.txt\&User=ANONYMOUS\&Password=anonymous\&SortMethod=h\%7C - \& Maximum Documents=1\&FuzzyDegree=0\&ImageQuality=r75g8/r75g8/x150y150g16/ i425\&Display $=$ hpfr\&DefSeekPage $=x \&$ SearchBack $=$ ZyActionL\&Back=ZyActionS\&BackDesc $=$ Results $\% 20$ page \&MaximumPages $=1 \& Z y$ Entry $=1 \&$ SeekPage $=x \& Z y P U R L$ 
35 Y. Sung-Mi, N. Hoe-Jung, K. Ji-In, Y. Jeong-Ki, L. Ga-Hee, L. Hong-Gil, J. Hun-Je, K. In-Ja. H. Ji-Ae, and K. Hyun-Koo: J. Soil Groundw. Environ. 23 (2018) 54. https://doi.org/10.7857/JSGE.2018.23.6.054

36 S. M. Mudge: Comparative Environmental Fate of Marine Lubricants (Unpublished manuscript, Exponent UK, 2010).

37 Y. Sung-Mi, N. Hoe-Jung, K. Ji-In, Y. Jeong-Ki, L. Ga-Hee, L. Hong-Gil, J. Hun-Je, K. In-Ja. H. Ji-Ae, and K. Hyun-Koo: J. Soil Groundw. Environ. 23 (2018) 54. https://doi.org/10.7857/JSGE.2018.23.6.054

38 Y. P. Cao and L. G. Yu: Runhuayou 5 (1999) 384. http://en.cnki.com.cn/Article_en/CJFDTotalRHYD199905003.htm

39 L. Jinjin: Henan Shiyou. 5 (2005) 626. http://en.cnki.com.cn/Article en/CJFDTotal-SYHN200505028.htm

40 J. Tang, X. Lu, Q. Sun, and W. Zhu: Agric. Ecosyst. Environ. 149 (2012) 109. https://doi.org/10.1016/ j.agee.2011.12.020

41 X. Wu, X. Zhang, S. Yang, H. Chen, and D. Wang: J. Am. Oil Chem. Soc. 77 (2000) 561. https://doi. org/10.1007/s11746-000-0089-2

42 M. Chuanguo and G. Ruihua: Nongye Gongcheng Xuebao. 11 (2010) 270. http://doi.org/10.3969/ j.issn.1002-6819.2010.11.047

43 C. Boshui, G. Lingyue, F. Jianhua, Z. Nan, W. Jiang, and W. Jiu: China Pet. Process. Petrochem. Technol. 3 (2015) 102. https://www.airitilibrary.com/Publication/alDetailedMesh?docid=zgsyjgysyhgjs201503014

44 O. N. Anand and V. K. Chhibber: J. Synth. Lubr. 23 (2006) 91. https://doi.org/10.1002/jsl.14

45 N. H. Jayadas, K. P. Nair, and G. Ajithkumar: Tribol. Int. 40 (2007) 350. https://doi.org/10.1016/ j.triboint.2005.09.021

46 M. Mohanraj, S. Jayaraj, and C. Muraleedharan: Int. J. Greenhouse Gas Control. 3 (2009) 108. https://doi. org/10.1016/j.ijggc.2008.07.003

47 K. G. Austin, A. Schwantes, and Y. Gu, P. S. Kasibhatla: Environ. Res. Lett. 14 (2019) 024007. https://doi. org/10.1088/1748-9326/aaf6db

48 T. S. Chang, R. Yunus, U. Rashid, T. S. Choong, D. R. A. Biak, and A. M. Syam: J. Oleo Sci. 64 (2015) 143. https://doi.org/10.5650/jos.ess 14162

49 T. D. Wahyuningsih and Y. S. Kurniawan: Proc. American Institute of Physics Conf. (AIP Publishing LLC, 2017) 020081. https://doi.org/10.1063/1.4978154

50 A. N. Annisa and W. Widayat: Materials Science, Engineering and Chemistry Web of Conf. (EDP Sciences, 2018) 06007-7. https://doi.org/10.1051/matecconf/201815606007

51 Thomson Reuters Practical Law: https://uk.practicallaw.thomsonreuters.com/2-524-2451?transitionType=Defa ult\&contextData $=($ sc.Default $)$ (accessed July 2019).

52 G. A. L. Canchumani: Used Lubricating Oils: A Study of Life Cycle Analysis of Re-refine System in Brazil. (COPPE/UFRJ, Rio de Janeiro, 2013). http://www.ppe.ufrj.br/images/publica\%C3\%A7\%C3\%B5es/doutorado/ Giancarlo_Alfonso_Lov\%C3\%B3n_Canchumani.pdf

\section{About the Authors}

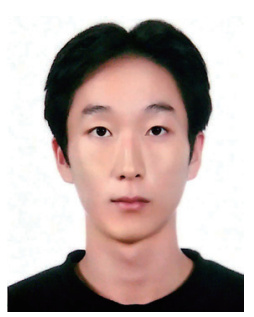

Seunghyeon Park is currently an M.S. degree student in Kangwon National University, Republic of Korea. His research interests include forest environment protection and eco-hydrology. (seasudal@kangwon.ac.kr)

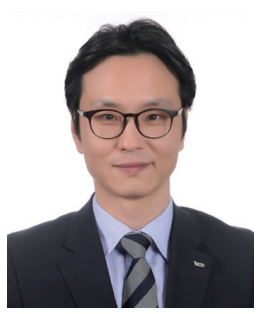

Byoungkoo Choi (corresponding author) received his B.S. and M.S. degrees from Kangwon National University, Republic of Korea, in 2002 and 2004, respectively, and his Ph.D. degree from Mississippi State University, USA, in 2011. From 2014 to 2015, he was a research scientist at the National Institute of Ecology, Republic of Korea. Since 2015, he has been an associate professor at Kangwon National University. His research interests include ecohydrology, watershed management, and forestry BMPs.

(bkchoi@kangwon.ac.kr) 